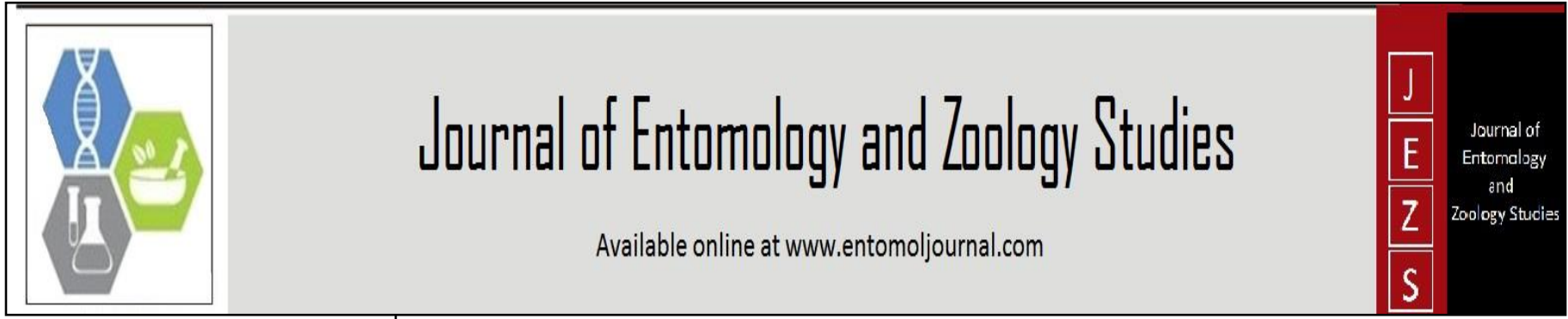

E-ISSN: 2320-7078

P-ISSN: 2349-6800

www.entomoljournal.com

JEZS 2021; 9(2): 06-13

(C) 2021 JEZS

Received: 04-01-2021

Accepted: 06-02-2021

Ramlatu Abubakar

(1) Department of Laboratory

Sciences, Federal Polytechnic,

Nasarawa, Nigeria

(2) Department of Biology,

Umaru Musa Yar'adua

University, Katsina, Nigeria

Mohammed Suleiman

Department of Biology, Umaru

Musa Yar'adua University,

Katsina, Nigeria

Nasir H Wagini

Department of Biology, Umaru

Musa Yar'adua University,

Katsina, Nigeria
Corresponding Author:

Ramlatu Abubakar

(1) Department of Laboratory

Sciences, Federal Polytechnic,

Nasarawa, Nigeria

(2) Department of Biology,

Umaru Musa Yar'adua

University, Katsina, Nigeria

\section{Phytochemical and insecticidal properties of some botanical extracts against the lesser grain borer, Rhyzopertha dominica F. (Coleoptera: Bostrichidae)}

\author{
Ramlatu Abubakar, Mohammed Suleiman and Nasir H Wagini
}

DOI: https://doi.org/10.22271/j.ento.2021.v9.i2a.8452

\section{Abstract}

Experiments were conducted in postgraduate laboratory of the Department of Biology of Umaru Musa Yar'adua University, Katsina (UMYUK) Nigeria, to analyze phytochemical properties and assess insecticidal effects of acetonic leaf extracts of Euphorbia balsamifera, Lawsonia inermis and Mitracarpus hirtus against Rhyzopertha dominica F. To analyze the phytochemicals of the test plants, preliminary tests were conducted to determine secondary metabolites while Gas Chromatography Mass Spectrum (GC-MS) was carried out to identify various active compounds present in the botanical extracts. Effects of the treatments on adult mortalities against $R$. dominica, adult emergence and grain weight losses were also determined. To determine percentage mortalities of $R$. dominica at 7 days after treatment (DAT), acetonic extracts of the botanicals at the concentrations of $6.25,12.50,25.00,50.00$, $100.00 \mathrm{mgml}^{-1}$ and permethrin powder at $11.20 \mathrm{mg} / 20 \mathrm{~g}$ were applied to $20 \mathrm{~g}$ of sorghum grains in different plastic bottles. None of the extracts or permethrin powder was added to the control. The experiment was arranged in a completely randomized design (CRD) and replicated three times. Findings of the study revealed the presence of alkaloids, carbohydrate, phytesterols, phenolic compounds, flavonoids, saponins, tannins and cardiac glycosides in the botanical extracts. The plant extracts resulted in adult mortality of $R$. dominica which ranged from 16.67 to $63.33 \%$ within 7 days after treatment (DAT). No adult emergence was observed in all the treated grains. Also, grain weight losses of the treated sorghum varied from 3.92 to $6.63 \%$. Acetonic extracts of the botanicals could therefore be utilized to reduce $R$. dominica infestations in stored sorghum.

Keywords: botanicals, phytochemicals, GC-MS analysis, $\mathrm{LC}_{50}$, mortality, $R$. dominica, toxicity

\section{Introduction}

Sorghum is the primary food crop in virtually all parts of northern Nigeria ${ }^{[1]}$. Sorghum is also used as animal feed, bio-fuel and extensively in brewing and the industrial demand for sorghum by beer manufactures is rising steadily in step with rising demand for their products [1].

Storage is an interim phase during transit of agricultural produce from producers to consumers. The main purpose of storage for small scale farmers in Africa is to ensure household supplies and seed for planting ${ }^{[2]}$.

Rhyzopertha dominica is a major cause of damage pest of wheat and rice around the world [3, 4]. Both larvae and adult produce frass and cause weight looses by feeding on grains. $R$. dominica infestation can reduce rice to dust ${ }^{[5]}$. There are three aspect of impact of $R$. dominica infestation which are loss in the quality of stored grain, loss in the quality of stored seeds ${ }^{[6]}$ and the cost to prevent or control infestation ${ }^{[7]}$ on wheat and rice. Larvae of $R$. dominica consume both germ and endosperm during their development in grain and thus provide more frass than Cryptolestes ferrugineus and Sitophilus granarius ${ }^{[8]}$.

In order to manage these infestations, chemical insecticides are widely used by farmers due to their rapid action. This leads to a search for alternative and environmental-friendly methods such as application of botanicals to control stored products insects pests. It is against this background that leaf extracts of Euphorbia balsamifera Aiton, Lawsonia inermis L. and Mitracarpus hirtus (L.) DC. were selected for their phytochemical screening as well as assessing their influence in reducing $R$. dominica infestations in stored sorghum. 
Materials and Methods

Collection, Identification and Preparation of Plant Materials

Leaves of Euphorbia balsamifera Aiton, Lawsonia inermis L. and Mitracarpus hirtus L., were collected from the bushes around Dabaibayawa village and identified at the Herbarium of the Department of Biology, Umaru Musa Yar'adua University, Katsina (UMYUK), All the plant leaves were shade dried in a well ventilated area in the Biology Laboratory 3 for 14 days before grinding and sieving them into fine powders through a laboratory sieve with $80 \mu \mathrm{m}$ aperture size. The powders were placed in well labeled black polythene bags separately and kept in laboratory shelf at room temperature prior to use. The conventional insecticide (permethrin $0.6 \%$ ) was purchased from insecticide vendor.

\section{Preparation of Samples for Phytochemical Screening}

Twenty grams of each of the plant powders was soaked into $100 \mathrm{ml}$ of each solvent (methanol, acetone and ethanol) for 48 $\mathrm{h}$ and filtered using Whatman No. 1 filter paper. The filtrate was evaporated using water bath until dry extracts were obtained which were used for preliminary phytochemical screening to detect the presence of secondary metabolites such as saponins, tannins, flavonoids, carbohydrates, phenolic compounds, terpanoids and cardiac glycosides ${ }^{[9]}$.

\section{Preliminary Phytochemical Screening of Leaf Extracts}

The different botanical extracts were subjected to preliminary screening using standard procedures for the detection of alkaloids, saponins, tannins, phenolic compounds, flavonoids, carbohydrates, phytosterols, terpanoids and cardiac glycosides as described hereunder.

\section{Test for alkaloids (Mayer's test)}

Three $\mathrm{ml}$ of extract were introduced into three different test tubes and then acidified with $1 \mathrm{ml}$ hydrochloric acid. Half $\mathrm{g}$ of the extract was diluted in $10 \mathrm{ml}$ of $1 \%$ aqueous hydrochloric acid and to each of these solutions, 4 drops of mayer, wadner and dragendroff reagents were separately added. A creamy white (mayer), reddish brown (wadner) and orange brown (dragendroff) precipitates indicated the presence of alkaloids [10].

\section{Test for carbohydrates (Molish's test)}

Molisch's test was adopted for carbohydrates test. Two g of the extracts were dissolved in $5 \mathrm{ml}$ of distilled water and filtered. Two drops of alcoholic naphthol solution were added to $2 \mathrm{ml}$ of the filtrate and $1 \mathrm{ml}$ of concentrated sulphuric acid was added slowly along the side of the test tube. A violent ring at the junction of two liquid confirmed the presence of carbohydrates ${ }^{[11]}$.

\section{Test for phytosterols (Liberman-Bruchard's test)}

Five $\mathrm{ml}$ of extract were treated with chloroform and the fitrate of that is treated with few drops of acetic anhydride. Then the solution was boiled and allowed to be cold, the formation of brawn ring at the junction of the test tube indicated the presence of phytosterols ${ }^{[11]}$.

\section{Test for terpenoids (Salkowaski test)}

Each of the plant extracts was taken in a test tube and a few pieces of tin plus 3 drops of thionyl chloride were added to it. A violet colour indicated the presence of terpenoid ${ }^{[12]}$.
Test for phenolic compounds (Ferric chloride test)

Two $\mathrm{ml}$ of acetonic leaf extract of the test botanicals were treated with a few drops of ferric chloride solution and the formation of bluish black colour proved the presence of phenols ${ }^{[11]}$.

\section{Test for saponins (Foam test)}

Two $\mathrm{ml}$ of the botanical extracts were vigorously shaken in a test tube for 2 minutes and observed for a stable persistent froth. Frothing in the test extract indicated the presence of saponins ${ }^{[10]}$.

\section{Test for tannins (Ferric chloride test)}

Two drops of $5 \%$ ferric chloride were added to $1 \mathrm{ml}$ of the test extract. A dirty green precipitate indicated the presence of tannins ${ }^{[10]}$.

\section{Test for flavonids (Alkaline reagent test)}

Ten $\mathrm{mg}$ of magnesium powder was added to $3 \mathrm{ml}$ of the test extract followed by 5 drops of concentrated hydrochloric acid. A red colouration indicated the presence of flavonoids ${ }^{[10]}$.

\section{Test for cardiac glycosides (Keller-kilani test)}

A mixture of $10 \mathrm{ml}$ of $5 \%$ sulfuric acid and $1 \mathrm{ml}$ of the test extract in a test tube was heated in boiling water for 15 minutes after which $10 \mathrm{ml}$ of Fehling's solution was added to the mixture and boiled for another 10 minutes. A brick-red precipitate indicated the presence of glycosides in the extract [10].

\section{Gas Chromatography Mass Spectrum (GC-MS) Analysis of the Test Botanicals}

Five $\mathrm{ml}$ of acetonic extract of each of the botanicals were taken to the Ahmadu Bello University, Zaria, Nigeria for GCMS analysis. The samples were analyzed using Thermo GCTrace Ultra (version 5.0) Gas Chromatography Interface to Thermo MS DSQ II Mass Spectrometer Instrument employing the following conditions: capillary standard non polar column ( $30 \times 0.25 \mathrm{~mm} \times 0.25 \mu \mathrm{m})$ and helium was used as carrier gas at a constant flow rate of $1 \mathrm{mlmin}^{-1}$. The oven temperature was kept at $70{ }^{\circ} \mathrm{C}$ and was programmed to reach $260{ }^{\circ} \mathrm{C}$ at a rate of $6{ }^{\circ} \mathrm{C} \mathrm{min}^{-1}$ and the mass range was $\mathrm{m} / \mathrm{z}$ 50650. The total running time was completed in 1 hour. The chromatogram obtained from gas chromatography was analyzed in mass spectrometry by comparing the mass spectra of unknown peaks with those stored in Willey 9 GC-MS library.

\section{Preparation of Extract for Toxicity Test}

One hundred grams of each of the plant powders were dissolved in $400 \mathrm{ml}$ of acetone in conical flasks in which the mouth were properly covered with cotton and kept in the laboratory at room temperature for $48 \mathrm{hrs}$. The mixture was first separated using muslin cloth and then filtered with Whatman No. 1 filter paper using vacuum pump (Dymax 14). The filtrates were placed in a water bath for the solvent to evaporate leaving the solid crude extracts.

\section{Rearing of Rhyzopertha dominica}

Whole grains of sorghum local variety called "Kaura" from Katsina central market were disinfected in an oven at $60{ }^{\circ} \mathrm{C}$ for 1 hour ${ }^{[13]}$ before using them as substrate for insect rearing. Twenty five pairs of adults of $R$. dominica obtained from Institute of Agricultural Research, Zaria (IAR), Nigeria 
were introduced into each of rearing bottles (500 $\mathrm{ml}$ capacity) containing $400 \mathrm{~g}$ of the disinfested sorghum. The bottles were covered with muslin cloth, secured with rubber bands and placed in an incubator at $30 \pm 2{ }^{\circ} \mathrm{C}$ and $70 \pm 5 \%$ r.h for oviposition. The insects were removed after seven days leaving the grains only for adult emergence. The emerged $F_{1}$ individuals were sieved from the grains and used for the experiments ${ }^{[14]}$.

Determination of Adult Mortality of Rhyzopertha dominica Twenty grams of disinfected sorghum grains were weighed into 15 plastic bottles $(250 \mathrm{ml}$ capacity). The plant extracts were applied at the rate of $6.25,12.50,25.00,50.00$ and $100.00 \mathrm{mgml}^{-1}$ to $20 \mathrm{~g}$ of sorghum grains in each of the bottles. Another bottle contained grains treated with $11.20 \mathrm{~g}$ of permethrin, while no extract was added to the control. The treatments containing extracts and permethrin were thoroughly mixed with the sorghum grains using glass rod to ensure thorough admixture and allowed the extracts to evaporate for 2 hrs. Thereafter, ten newly emerged adults of $R$. dominica were introduced into each of the treated and untreated grains. Mouths of the bottles were covered with muslin cloth, secured with rubber bands and then kept in an incubator at $30 \pm 2^{\circ} \mathrm{C}$ and $70 \pm 5 \%$ R.H. and arranged in a completely randomized design (CRD) with three replicattions. Dead insects were removed, counted and recorded daily for 7 days. This was followed by removing all the remaining insects (dead and alive) and leaving the grains only. The plastic bottles containing the grains were then kept under the aforementioned environmental conditions until emergence of new individuals of the insect ${ }^{[15]}$.

Examination of Adult Emergence of Rhyzopertha dominica Adult emergence of $R$. dominica from treated and untreated grains was examined immediately after determination of adult mortality. This was done by sieving all the remaining insects from the treated and untreated sorghum grains and the containers were left undisturbed in the laboratory until the emergence of new individuals. The number of emerged insects was recorded daily for 14 days.

\section{Assessment of Weight Losses in Treated Sorghum Grains Infested by Rhyzopertha dominica}

The level of damage caused by $R$. dominica on the sorghum grains were studied from the same set up. Sorghum grains from each of the containers were sieved, weighed and recorded at 49 days after introduction of the insects. Grain weight loss was determined by using the following formula [16].

Grain Weight Loss $(\%)=\frac{\text { Initial Weight }(\mathrm{g})-\text { Final Weight }(\mathrm{g})}{\text { Initial Weight }(\mathrm{g})} \times 100$

\section{Statistical Analysis}

Data were analyzed using GraphPad Insta 3. Normality test was done using KS test and all data were found to be non parametric. Therefore, Kruskal-Wallis test was employed to test if there was any significant difference in adult mortality among the insects and weight losses of treated sorghum grains infested by $R$. dominica. Significantly different means were separated using Dunn's multiple test for non parametric data. All analyses were performed at $p<0.05$.

\section{Results}

Secondary Metabolites Present in Acetonic Leaf Extracts of Three Botanicals

Preliminary phytochemical screening of E. balsamifera, $L$. inermis and $M$. hirtus leaves revealed the presence of 9 secondary metabolites namely; alkaloids, carbohydrates, phytesterols, phenolic compounds, flavonoids, saponins, tannins and cardiac glycosides (Table 1). Alkaloids, carbohydrates, phenolic compounds and flavonoids were presence in methanolic leaf extracts of all the botanicals. Phytesterols and cardiac glycosides were absent in $E$. balsamifera. Likewise saponins and terproids were not found in L. inermis. Acetonic extracts of all the test botanicals contained carbohydrates, phytesterols, saponnins, tannins flavonoids, terproids, and cardiac glycosides, whereas no alkaloids and phenolic compounds were found in M. hirtus. The results further showed that ethanolic extracts contained phytesterols, saponins, phenolic compound, flavonoids, terpnoids and cardiac glycosides in all the botanicals. However, alkaloids and carbohydrates were absent in $E$. balsamifera, while saponins, phenolic compounds and cardiac glycosides were not found in M. hirtus (Table 1).

Gas Chromatography-Mass Spectrum (GC-MS) Analysis of Acetonic Leaf Extracts of Three Botanicals

Gas chromatography-mass spacterum (GC-MS) of $E$. balsamifera extracts is shown in Table 2. A total of 20 compounds were found among which Oleic acid Eicosyl ester had the highest molecular weight $(562.99 \mathrm{~g} / \mathrm{mol})$ followed by Cyclopentene (4-octyldodecyl) $(350.70 \mathrm{~g} / \mathrm{mol})$ and then Hexanoic acid,2-,hydroxide methyl ester $\left(316.50 \mathrm{gmol}^{-1}\right)$, but the least $\left(34.01 \mathrm{gmol}^{-1}\right)$ was found in hydrogen peroxide. In terms of area, 2-ethyl-2-hexen-1-ol was the highest (8.28\%) followed by 5-methyl-2-hexanoic acid (7.17\%) and heptadecanoic acid -16-methyl ester $(6.90 \%)$, while the least $(0.06 \%)$ was found in heptadecanal (Table 2$)$.

Table 3 shows the GC-MS analysis of acetonic leaf extract of L. inermis. A total of 8 compounds were found in the botanical. Pennogenin di-acetate had the highest molecular weight $(514.70 \mathrm{~g} / \mathrm{mol})$ followed by 2-butyl-6,7-dichlopentyl1-oxo-2,3-dihydro-1h-inden-5-yl) acetic acid (399.30 g/mol) while the least was found in N,N-diethylethane-1,2-diamine $(116.20 \mathrm{~g} / \mathrm{mol})$. Further, percentage area varied among the identified compounds from 1.22 to $39.63 \%$ (Table 3 ).

A total of 5 compounds were found when GC-MS analysis of acetonic leaf extract of $M$. hirtus was conducted (Table 4). Lanosta-7-9(11)20-triene-3-becta-18 diol, di-acetate had the highest molecular weight $(524.77 \mathrm{~g} / \mathrm{mol})$, followed by pennogenin diacetate $(514.70 \mathrm{~g} / \mathrm{mol})$ and cis -13-octadecanoic acid methyl ester $(296.49 \mathrm{~g} / \mathrm{mol})$ but cis-vaccenic acid $(282.50 \mathrm{~g} / \mathrm{mol})$ had the lowest molecular weight. The percentage area ranged from 4.96 to $44.90 \%$.

\section{Adult Mortality of Rhyzopertha dominica Exposed to Acetonic Leaf Extracts of Three Botanicals}

Results from this study show that adult mortality of $R$. dominica in treated sorghum grains differed with varying concentrations of the botanical extracts. Highest (63.33\%) mortality among the botanical treatments was recorded in sorghum treated with $100.00 \mathrm{mgml}^{-1} \mathrm{M}$. hirtus, while the least $(16.67 \%)$ was in treatments with $6.25 \mathrm{mgml}^{-1}$ E. balsamifera within 7 days after treatment (DAT). Permethrin powder resulted in $66.67 \%$ mortality while no insect was found dead in the untreated grains (Figure 1). Kruskal-Wallis test 
indicated that adult mortality of $R$. dominica was significantly different $(p<0.05)$ among treatments at all concentrations applied.

\section{Adult Emergence of Rhyzopertha dominica Exposed to Acetonic Leaf Extracts}

There were no adult emergence of $R$. dominica in the sorghum grains treated with acetonic leaf extracts of $E$. balsamifera, L. inermis and M. hirtus. However, the mean number of adult emergence in untreated grains was 42 .
Weight Losses of Treated Sorghum Infested by Rhyzopertha dominica

Results obtained from this study showed a significant difference $(p<0.05)$ in grain weight loss among the different botanicals and permethrin applied at varying concentrations. Highest weight losses were recorded in the sorghum treated with lower concentrations of the botanical extracts which decreased with higher concentrations following the order $100.00<50.00<25.00<12.5<6.25 \mathrm{mgml}^{-1}$ (Figure 2). The result shows that mean weight loss in the permethrin treatment was $0.27 \%$, while that in the control was $12.27 \%$.

Table 1: Preliminary Phytochemical Screening of Some Botanicals Using Different Extraction Solvents

\begin{tabular}{|c|c|c|c|c|c|c|c|c|c|}
\hline \multirow{2}{*}{ Botanicals } & \multicolumn{9}{|c|}{ Methanolic Extracts } \\
\hline & AKL & CHO & PHT & PHC & SPN & TAN & FLV & TPR & CGC \\
\hline E. balsamifera & + & + & - & + & + & + & + & + & - \\
\hline L. inermis & + & + & + & + & + & + & + & - & + \\
\hline \multirow[t]{2}{*}{ M. hirtus } & + & + & + & + & + & + & + & + & + \\
\hline & & \multicolumn{8}{|c|}{ Acetonic Extracts } \\
\hline E. balsamifera & + & + & + & + & + & + & + & + & + \\
\hline L. inermis & + & + & + & + & + & + & + & + & + \\
\hline \multirow[t]{2}{*}{ M. hirtus } & - & + & + & - & + & + & + & + & + \\
\hline & & \multicolumn{8}{|c|}{ Ethanolic Extracts } \\
\hline E. balsamifera & - & - & + & + & + & + & + & + & + \\
\hline L. inermis & + & + & + & + & + & - & + & + & + \\
\hline M. hirtus & + & + & + & - & + & + & + & + & - \\
\hline
\end{tabular}

AKL = Alkaloids $;$ CHO = Carbohydrates $;$ PHT $=$ Phytosterols; SPN $=$ Saponins PHC $=$ Phenolic compounds; TAN $=$ Tannins; FLV $=$ Flavonoids; TPR $=$ Terproids; CGC $=$ Cardiac glycosides $;+=$ Presence $;-=$ Absence

Table 2: Gas Chromatography Mass Spectrum (GC-MS) Analysis of Acetonic Leaf Extract of E. balsamifera

\begin{tabular}{|c|c|c|c|c|c|}
\hline S/No. & $\begin{array}{c}\text { Retention Time } \\
\text { (min) }\end{array}$ & Name of Compound & $\begin{array}{c}\text { Molecular } \\
\text { Formula }\end{array}$ & $\begin{array}{c}\text { Molecular Weight } \\
(\mathrm{g} / \mathrm{mol})\end{array}$ & $\begin{array}{c}\text { Area } \\
(\%)\end{array}$ \\
\hline 1 & 1.91 & Trimathylene oxide & $\mathrm{C}_{3} \mathrm{H}_{6} \mathrm{O}$ & 58.08 & 1.89 \\
\hline 2 & 5.24 & Dodecanoic acid & $\mathrm{C}_{12} \mathrm{H}_{24} \mathrm{O}_{2}$ & 200.32 & 0.68 \\
\hline 3 & 7.70 & Tetradecanoic acid & $\mathrm{C}_{14} \mathrm{H}_{28} \mathrm{O}_{2}$ & 228.37 & 0.22 \\
\hline 4 & 10.04 & Pentradecanoic acid 14-methl methyl ester & $\mathrm{C}_{17} \mathrm{H}_{34} \mathrm{O}_{2}$ & 270.45 & 0.18 \\
\hline 5 & 11.86 & N-hexadecanoic acid & $\mathrm{C}_{16} \mathrm{H}_{32} \mathrm{O}_{2}$ & 256.42 & 1.69 \\
\hline 6 & 13.92 & 11-octadecenoic acid, methyl ester & $\mathrm{C}_{19} \mathrm{H}_{36} \mathrm{O}_{2}$ & $296 . .49$ & 1.15 \\
\hline 7 & 14.43 & Heptadecanoic acid 16-methyl methyl ester & $\mathrm{C}_{19} \mathrm{H}_{38} \mathrm{O}_{2}$ & 298.50 & 6.90 \\
\hline 8 & 16.04 & Oleic acid Eicosyl ester & $\mathrm{C}_{38} \mathrm{H}_{74} \mathrm{O}_{2}$ & 562.99 & 6.13 \\
\hline 9 & 22.49 & Trans -13-octadecenoic acid & $\mathrm{C}_{20} \mathrm{H}_{28} \mathrm{O}_{2}$ & 310.50 & 0.14 \\
\hline 10 & 24.83 & Octadecanoic acid & $\mathrm{C}_{18} \mathrm{H}_{36} \mathrm{O}_{2}$ & 284.50 & 0.22 \\
\hline 11 & 25.04 & Cis-12-octadecenoic acid methyl ester & $\mathrm{C}_{19} \mathrm{H}_{36} \mathrm{O}_{2}$ & 296.50 & 0.19 \\
\hline 12 & 25.08 & Heptadecanal & $\mathrm{C}_{17} \mathrm{H}_{34} \mathrm{O}$ & 254.50 & 0.06 \\
\hline 13 & 25.97 & Ethyl pentadecanoate & $\mathrm{C}_{17} \mathrm{H}_{34} \mathrm{O}_{2}$ & 270.50 & 0.14 \\
\hline 14 & 26.52 & Cyclopentene (4-octyldodecyl) & $\mathrm{C}_{25} \mathrm{H}_{50}$ & 350.70 & 1.55 \\
\hline 15 & 26.76 & Carbamic,-2-hydroxyprpyl ester & $\mathrm{C}_{4} \mathrm{H}_{9} \mathrm{NO}_{3}$ & 119.12 & 0.62 \\
\hline 16 & 27.12 & Cis vaccenic acid & $\mathrm{C}_{18} \mathrm{H}_{34} \mathrm{O}_{2}$ & 282.46 & 0.47 \\
\hline 17 & 27.48 & Hydrogen peroxide & $\mathrm{H}_{2} \mathrm{O}_{2}$ & 34.02 & 0.59 \\
\hline 18 & 28.42 & 5-Methyl -2-hexanoic acid & $\mathrm{C}_{7} \mathrm{H}_{14} \mathrm{O}_{2}$ & 130.18 & 7.17 \\
\hline 19 & 29.37 & Hexanoic acid,2-,hydroxide methyl ester & $\mathrm{C}_{17} \mathrm{H}_{34} \mathrm{O}_{4}$ & 316.50 & 2.05 \\
\hline 20 & 30.88 & 2-Ethyl -2-hexen -1-ol & $\mathrm{C}_{8} \mathrm{H}_{16} \mathrm{O}$ & 128.21 & 8.28 \\
\hline
\end{tabular}

Table 3: Gas Chromatography Mass Spectrum (GC-MS) Analysis of Acetonic Leaf Extract of L. inermis

\begin{tabular}{|c|c|c|c|c|c|}
\hline S/No. & $\begin{array}{c}\text { Retention } \\
\text { Time (min) }\end{array}$ & Name of Compound & $\begin{array}{l}\text { Molecular } \\
\text { Formula }\end{array}$ & $\begin{array}{c}\text { Molecular } \\
\text { Weight }(\mathrm{g} / \mathrm{mol})\end{array}$ & $\begin{array}{c}\text { Area } \\
(\%)\end{array}$ \\
\hline 1 & 13.85 & trans-13-octadecanoic-acid methyl ester & $\mathrm{C}_{19} \mathrm{H}_{36} \mathrm{O}_{2}$ & 296.50 & 33.09 \\
\hline 2 & 15.43 & Cis -13-octadecenoic acid & $\mathrm{C}_{18} \mathrm{H}_{34} \mathrm{O}_{2}$ & 282.50 & 39.65 \\
\hline 3 & 29.00 & 2-Butyl -6,7-dichlopentyl-1-oxo-2,3-dihydro-1h-inden-5-yl) acetic acid & $\mathrm{C}_{20} \mathrm{H}_{24} \mathrm{Cl}_{2} \mathrm{O}_{4}$ & 399.30 & 38.05 \\
\hline 4 & 29.42 & $\mathrm{~N}, \mathrm{~N}$-diethylethane-1,2-diamine & $\mathrm{C}_{6} \mathrm{H}_{16} \mathrm{~N}_{2}$ & 116.21 & 22.63 \\
\hline 5 & 29.76 & Methacrolein diacetate & $\mathrm{C}_{8} \mathrm{H}_{12} \mathrm{O}_{4}$ & 172.18 & 34.88 \\
\hline 6 & 29.08 & Cycolode canol, 1-aminomethyl- & $\mathrm{C}_{13} \mathrm{H}_{27} \mathrm{NO}$ & 213.36 & 4.53 \\
\hline 7 & 29.19 & Pennogenin di-acetate & $\mathrm{C}_{31} \mathrm{H}_{46} \mathrm{O}_{6}$ & 514.70 & 1.22 \\
\hline 8 & 29.91 & 2-(2,2-dimethyl-1,3-dioxolan-4-yl)ethan-1-ol & $\mathrm{C}_{7} \mathrm{H}_{14} \mathrm{O}_{3}$ & 146.18 & 1.26 \\
\hline
\end{tabular}


Table 4: Gas Chromatography Mass Spectrum (GC-MS) Analysis of Acetonic Leaf Extract of M. hirtus

\begin{tabular}{|c|c|c|c|c|c|}
\hline S/No. & Retention Time (min) & Name of Compound & Molecular Formula & Molecular Weight (g/mol) & Area $(\%)$ \\
\hline 1 & 13.60 & 9,12-octadecenoic acid methyl ester & $\mathrm{C}_{19} \mathrm{H}_{34} \mathrm{O}_{2}$ & 294.50 & 16.34 \\
\hline 2 & 13.72 & Cis -13-octadecenoic acid methyl ester & $\mathrm{C}_{19} \mathrm{H}_{36} \mathrm{O}_{2}$ & 296.49 & 21.77 \\
\hline 3 & 15.21 & Cis-vaccenic acid & $\mathrm{C}_{18} \mathrm{H}_{34} \mathrm{O}_{2}$ & 282.50 & 44.90 \\
\hline 4 & 27.49 & Pennogenin di-acetate & $\mathrm{C}_{31} \mathrm{H}_{46} \mathrm{O}_{6}$ & 514.70 & 12.02 \\
\hline 5 & 27.87 & Lanosta-7-9(11)20-triene-3beta-18 diol, di-acetate & $\mathrm{C}_{34} \mathrm{H}_{52} \mathrm{O}_{4}$ & 524.77 & 4.96 \\
\hline
\end{tabular}

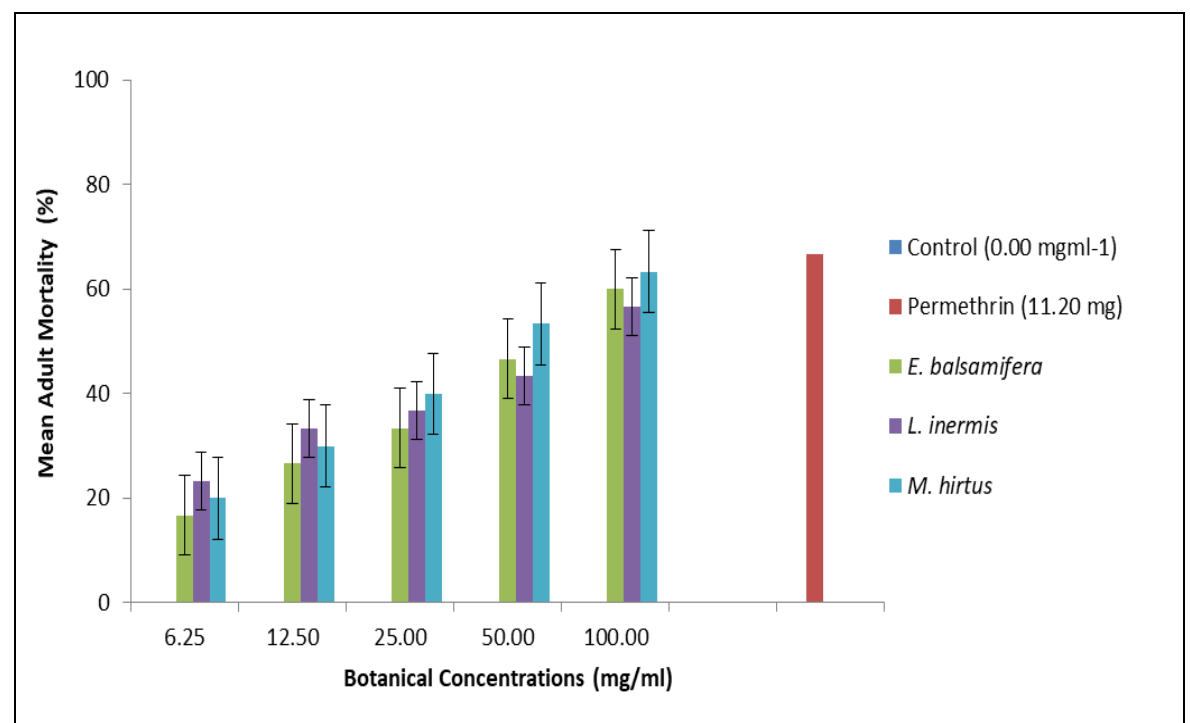

Fig 1: Mean Adult Mortality of $R$. dominica Exposed to Acetonic Leaf Extract of Three Botanicals at 7 Days After Treatment

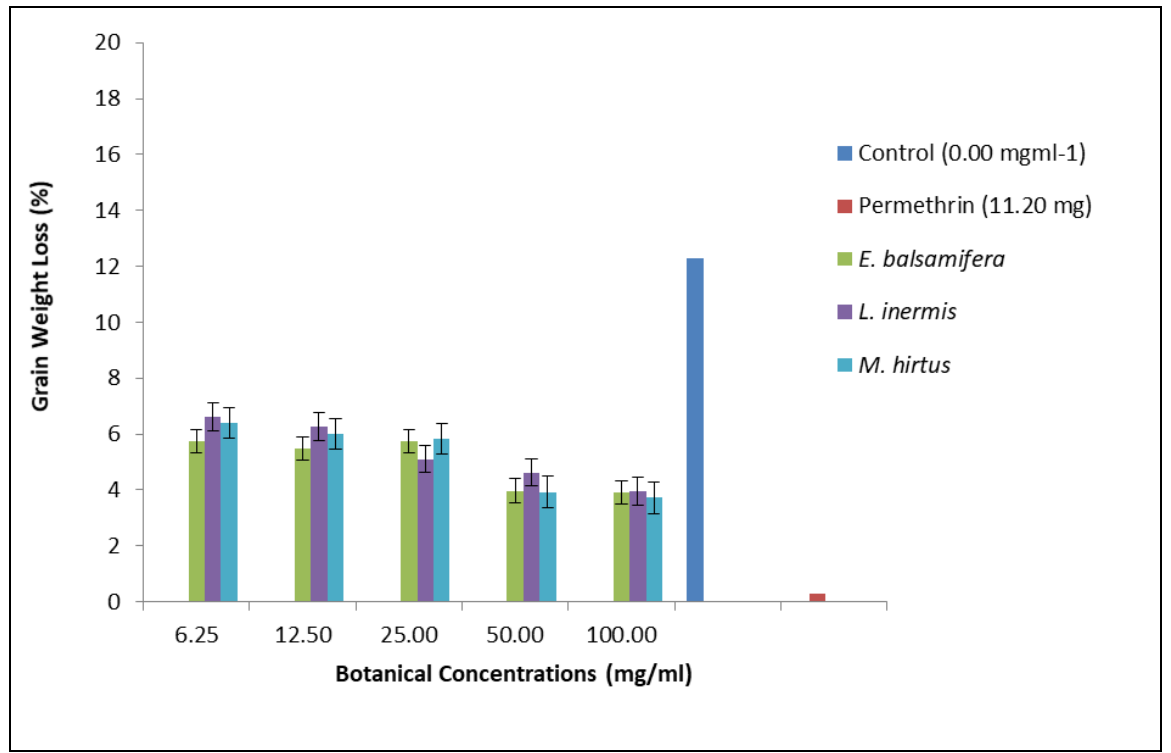

Fig 2: Weight Losses in Sorghum Grins Treated with Three Acetonic Leaf Extracts and Infested by R. dominica

\section{Discussion \\ Phytochemical compounds of the selected botanicals with insecticidal properties}

Findings of this study revealed that E. balsamifera, L. inermis and $M$. hirtus were rich in most of the secondary metabolites such as alkaloids, carbohydrates, saponins, phytesterols, phenolic compound, tannins, flavonoids, terproids and cardiac glycocisides. These chemical constituents were reported to show insecticidal and medicinal activities ${ }^{[17,18]}$.

It was reported that three insecticidal ingredients were isolated from the total alkaloids complex of Cynanchum mongolicum, these three alkaloids exhibited marked insecticidal activity on Spodoptera litura and Lipaphis erysimi Ge et al. ${ }^{[19]}$.

Furthermore, It was stated that tannins can enter haemolymph of the insect through the peritrophic envelop of the gut ${ }^{[20]}$.
Henn ${ }^{[21]}$ observed that peritrophic envelop of insects are capable of connecting to tannins by attaching to carbohydrate of the envelops. Hydrolysable tannins of oak are well known as phenolics, which can negatively influence the growth of the gypsy moth ${ }^{[22]}$.

Another finding by Upasani et al. ${ }^{[23]}$ showed that, flavonoids are major class of chemicals constituting $5-10 \%$ of known secondary metabolites involved in plant defense mechanisms by exerting toxic effects on insects. Their biogenesis is reported in response to stress conditions besides their natural presence in measured quantities the phenyl propanoid (cinnamate CoA) pathway is mainly involved in biosynthesis of all known flavonoids.

Different hypotheses on the mode of action have been drawn so far to explain the insecticidal activities of saponins,. They may pose a repellent or deterrent activity as suggested by 
Sylwia et al. ${ }^{[24]}$. Saponins may also affect the food uptake by slowing the passage of in the insect gut, perhaps due to a reduction of the digestibility ${ }^{[25]}$. These can secondarily influence food uptake, and as a consequences the nutrient uptake and growth. Saponins were also found to increase the permeability of plasma membrane and they are known to course lysis of erythrocytes in vitro ${ }^{[26]}$.

In the present study, GC-MS analysis confirmed the presence of different compounds in acetonic leaf extracts of $E$. balsamifera, L. inermis and M. hirtus. Some of the isolated compounds such as oileic acid Eicosyl ester, decanoic acid, hydrogen peroxides and N,N-diethyl nediamine were reported to have some insecticidal properties ${ }^{[27,28]}$. Also, Oileic acid has the property of insectifuge, anti-inflamatory, cancer preventive and hypercholesterols ${ }^{[27]}$. Furthermore, decanoic acid can be used as insecticide (PT18). Decanoic acid kills insect upon contact with a sufficient dose with a delay of a few hours up to seven days depending on the species and the individual. It is speculated that the active substance damages the chitin cuticle of arthropods leading to desiccation ${ }^{[28]}$.

\section{Effect of acetonic botanical extracts on the survival of $\boldsymbol{R}$. dominica}

Findings of this study revealed that acetonic extracts of $E$. balsamifera, L. inermis and $M$. hirtus_were effective in causing adult mortality of $R$. dominica in stored sorghum. It was observed that the mortality was directly proportional to varying concentrations used for the study. This is supported by findings of Alvi et al. ${ }^{[29]}$ who reported that adult mortality of $R$. dominica increased from 27.83 to $72.11 \%$ when the concentration of leaf extracts of Rhazya stricta was raised from 5 to $20 \%$.

This study has also found that extension of exposure periods increased adult mortality of $R$. dominica in treated sorghum grains concurring with Alvi et al. ${ }^{[29]}$ who reported that Rhazya stricta leaf extract caused significant mortality against $R$. dominica which increased with increase in exposure time. Similarly, Ileke and Bulus ${ }^{[30]}$ reported that adult mortality of $R$. dominica in wheat grains treated with A. indica and Piper guineense increased with increase in exposure period.

Findings of this study have revealed that leaves of $E$. balsamifera, L. inermis and M. hirtus were significantly toxic against adult $R$. dominica causing considerable adult mortality within 7 days. Similar results were recorded by Suleiman and Suleiman ${ }^{[31]}$ that $90.00 \%$ adult mortality of Callosobruchus maculatus was observed in cowpea treated with leaf powder of E. balsamifera at $1.0 / 20 \mathrm{~g}(\mathrm{w} / \mathrm{w})$ within 96 hours of exposure.

The promising effect of $L$. inermis on the survival of $R$. dominica in this study agrees with previous report that $100 \%$ mortality of Trogoderma granarium exposed to 1, 2, 4 and $6 \%$ of leaf powder of the botanical was achieved at 14 days after treatment ${ }^{[32]}$.

There is scanty information on the efficacy of acetonic extract of $M$. hirtus against $R$. dominica. However, Suleiman et al. ${ }^{[33]}$ reported that ethanolic extract of the plant species caused in high mortality of $S$. zeamais. The mortalities of $R$. dominica exposed to the plant extracts reported in this study could have been possible due to obstruction of spiracle of the insect body, thus impairef respiration which led to death of the insect ${ }^{[33]}$.

Acetonic extract of E. balsamifera, L. inermis and M. hirtus used at different concentrations were found to have toxicity similar to permethrin powder against $R$. dominica, even though the beetles responded faster in permethrin than the botanical extracts. Permethrin has been discribed as a synthetic pyrethroid that act by interfering with the electric signal passing down the axon of insect nerval cells leading to loss of coordination and ultimate death ${ }^{[33]}$

All the three botanicals in different concentrations were effective against the beetle. This was possible because plant contain secondary metabolites which are enormous storehouse of compounds such as alkaloids, flavonoids, terproids, saponins, tannins and cardiac glycosides found in the leaf extracts of $E$. balsamifera, L. inermis and $M$. hirtus.Presences of alkaloids, flavonoids, saponins and tannins in the acetonic extract of the plant leaf was concluded to be of insecticidal effects against $R$. dominica.

\section{Effect of acetonic leaf extracts on adult emergence of $\boldsymbol{R}$. dominica}

All the three botanicals tested had total inhibition rate in adult emergence of $R$. dominica in sorghum grains treated with acetonic leaf extracts as no adult had emerged. Complete suppression of adult emergence of $R$. dominica by acetonic leaf extract of the test botanicals is in accordance with other findings. For instance, Suleiman et al. ${ }^{[34]}$ reported that complete inhibition of adult emergence of $S$. zeamais was achieved in grains treated with methanolic and ethanolic extracts of E. balsamifera, L. inermis and M. hirtus.

It could be possible that the complete inhibition in adult emergence of $R$. dominica by acetonic leaf extract of the test botanicals and permethrin might be due to total mortality observed some days after treatment. Also botanicals might be toxic to the few eggs deposited and as such led to elimination of the adult emergence of $R$. dominica. Concurring with Chudasama et al. ${ }^{[35]}$ that toxic substance present in the extract may enter into the egg through chorion and suppressed further embryonic development.

Non- emergence of $R$. dominica adults in the treated sorghum grains could be as a result of high mortality of adult insect observed some days after treatment, thus disrupting mating and sexual communication as well as deterring female from laying eggs and complete suppression of the developmental stages of insect ${ }^{[35]}$. Reduced adult emergence could be due to high mortality of the insect which might consequently reduce the rate of mating and oviposition ${ }^{[34,35]}$.

\section{Effect of acetonic leaf extracts on sorghum grain damage infested by $R$. dominica}

The acetonic leaf extract of E. balsamifera, L. inermis and $M$. hirtus used in this study were found to be effective in protecting the sorghum grains from damage caused by $R$. dominica. These might be attributed to the insecticidal activities of the botanicals against $S$. zeamais and $C$. maculatus as observed by others [31,36]. Similar observations were made by Adedire and Ajayi ${ }^{[37]}$ who reported $65.24 \%$ damage of maize grain caused by $S$. zeamais treated with 1.0 $\mathrm{ml} / 10 \mathrm{~g}$ acetonic extract of $C$. sinensis.

\section{Conclusion}

Phytochemical screening of the test botanicals has shown the presence of various bioactive compounds some of which have been reported to be of insecticidal properties. Findings of this study revealed that the acetonic leaf extracts of $E$. balsamifera, L. inermis, and $M$. hirtus had a great effect in adult mortality of $R$. dominica.

The acetonic leaf extract of E. balsamifera, L. inermis and $M$. hirtus tested in this study were found to be effective in 
protecting the sorghum grains from damage caused by $R$. dominica due to observed high mortality of the insect, nonemergence of $F_{1}$ generation and few perforations to the grains.

\section{Acknowledgement}

The authors are grateful to the management of Umaru Musa Yar'adua University, Katsina, for providing laboratory facilities for this study.

\section{References}

1. USDA. Nigeria grain and feed. Annual Grain Report, Number NI11015. United States Department of Agriculture 2011, 10.

2. Adetunji MO. Economics of maize storage techniques by farmers of Kwara State, Nigeria. Pak. J Soc Sci 2007;4(3):442-450.

3. Flinn PW, Hagstrum DW, Reed C, Phillips TW. Simulation model of $R$. dominica population dynamics in concrete grain bins. Journal of Stored Products Research. 2004;40(1):39-45.

4. Chanbanga Y, Arthur FH, Wilde GE, Throne JE. Efficacy of diatomaceous earth and methoprene, alone and in combination against Rhyzopertha dominica $(\mathrm{F})$ in rough rice. Journal of Stored Products Research 2007;43(4):396:401.

5. Emery RN, Nayak MK. Pest of stored grains. In: Bailey, PT (Ed.). Pest of field crops and postures: Identification and control. CSIRO Publishing, Collingwood, Victoria, Australia 2007, 40-62.

6. Sanchez-Marinez RI, Cortez-Rocha MO, Ortega-Dorame F, Morales-Valdes M, Silveira MI. End-use quality of flour from $R$. dominica infesting wheat. Cereal Chemistry 1997;74(4):481-483.

7. Cuperus GW, Noyes RT, Fargo WS, Clary BL, Arnold DC, Anderson K. Management practice s in a high-risk stored-wheat system in Oklahoma. Bulletin of the Entomological Society of America 1990;36(2):129-134.

8. Campbell A, Sinha RN. Damage of wheat by feeding of some stored product beetles. Journal of Economic Entomology 1976;69(1):11-13.

9. Ajuru GM, Light FW, Ajuru G. Qualitative and quantitative phytochemical screening of some plant used in Ethnomedicine in Niger Delta Region of Nigeria. Journal of Food and Nutrition Sciences 2017;5(5):1982005.

10. Idris MM, Mudi SY, Datti Y. Phytochemical screening and mosquito Repellency Activity of the stem bark extract of E. balsamifera (Ait), Chem Search Journal, 2014;5(2):46-51.

11. De Silva OG, Abeysundara TA, Aponso MMW. Extraction methods, quantitative and qualitative techniques for screening of phytochemicals from plants. American Journal of Essential Oils and Natural Products 2017;5(2):29-32.

12. Iqbal MJ, Hanif S, Mahmood Z, Anwar F, Jamil A. Antioxidant and antimicrobial activities of Chowlai (Amaranthus viridis L.) leaf and seed extracts. Journal of Medicinal Plants Research 2012;6(27):4450-4455. DOI: 10.5897/JMPR12.822.

13. Asmanizar AD, Idris AB. Effect of four selected plant powder as rice grain protectant against Sitophilus zeamais (Coleoptera: Curculionidae). Sains Malaysiana 2012;41(7):863-869.

14. Sani I, Suleiman M. Insecticidal activities of some plant extracts against the cowpea beetle, Callosobruchus maculatus F. (Coleoptera: Chrysomelidae). Journal of Biopesticides and Environment 2017;4(1):7-14.

15. Suleiman M. Efficacy of some spices as sorghum grain protectants against Sitophilus zeamais Motschulsky (Coleoptera: Curculionidae). African Journal of Agricultural Research 2014;9(9):841-845.

16. Suleiman M, Suleiman FL. Efficacy of powder of Senna obtusifolia (L.) and Mitracarpus hirtus (L.) DC. On the survival of Sitophilus zeamais Motschulsky (Coleoptera: Curculionidae) on sorghum grain during storage. Entomology and Applied Science Letters 2015;2(1):3438.

17. Sofoware A. Medicinal plants and traditional medicine in Africa. Spectrum Book Ibadan 1993, 150.

18. Doughary JH, El-Mahmood AM, Tyoyina I. Antimicrobial activity of leaf extracts of Sennaobtusifolia (L.). African Journal of Pharmacy and Pharmacology. 2008;2(1):007-013.

19. Ge Y, Liu P, Yang R, Zhang L, Chen H, Camara I et al. Insecticidal constituents and activity of alkaloids from Cynanchum magolicum. Molecule 2015;20(9):1748317492.

20. Berbehenn RV, Martin MM. Tannin sensitivity in larvae of Malacosoma disstria (Lepidoptera), roles of the petitrophic envelop and midgut oxidation. Journal of Chemical Ecology 1994;20(8):1985- 2001.

21. Henn MW. Adsorption von tanninen aus eichenblattern an kohlen-hydrathaltiger verbindungn enblattern, mitt. Dutsch. Gesell. Entomol 1997;11:495-499.

22. Rossiter MC, Schultz JC, Baldwin IT. Relationships among defoliation, red oak phenolic and gypsy moth growth and reproduction. Ecology 1988;69:267-297.

23. Upsani S, Koter M, Mendki S, Maheshwari V. Partial characterization and insecticidal properties of Ricinus communis L. foliage flavonoids. Pest Management Science 2003;59(12):1349-1354.

24. Sylwia G, Bogumil WL. Effect of low and high saponins lines of alfalfa on pea aphid. Journal of Insect Physiology 2006;52:737- 743 .

25. Adel MM, Sehnal F, Jurzysta M. Effects of Alfafa saponins on the moth Spodoptera littoralis. Journal of Chemical Ecology 2000;26:1065-1078.

26. Francis G, Kerem Z, Makkar H, Becker K. The biological action ofsaponins in animal system, a review. Journal of Nutrition 2002;88:586-605.

27. Sheela D, Uthayakumari F. GC-MS analysis of bioactive constituents from coastal sand dune taxon - Sesuvium portulacastrum (L.). Bioscience Discovery 2013;4(1):4753.

28. EU. Decanoic Acid (PT 18, 19). Assessment Report, European Union 2013, 86.

29. Alvi M, Iqbal N, Bashir MA, Rehmani MIA, Ullah Z, Saeed Q et al. Efficacy of Rhazya stricta leaf and seed extracts against Rhyzopertha dominica and Trogoderma granarium. Kuwait Journal of Science, 2018;45(3):64-71.

30. Ileke KD, Bulus DS. Evaluation of contact toxicity and fumigant effect of some medicinal plants and pirimiphos methyl powders against cowpea bruchid, Callosobruchus maculatus (Fab.) (Coleoptera: Chrysomelidae) in stored cowpea seeds. Journal of Agricultural Science, 2012;4(4):279-284.

31. Suleiman M, Suleiman HY. Control of Callosobruchus maculatus (F.) (Coleoptera: Bruchidae) using leaf 
powders of Euphorbia balsamifera L. and Lawsonia inermis L. International Journal of Science, Environment and Technology 2014;3(1):100-109.

32. Al-Moajel NH. Testing some various botanical powders for protection of wheat grain against Trogoderma granarium Everts. Journal of Biological Science 2004;4(5):592-597.

33. Suleiman M, Rugumamu CP, Ibrahim ND. Insecticidal toxicity of some botanical extracts against $S$. zeamais Motsch (Coleoptera: Curculionidae) in stored sorghum grain in Nigeria. Journal of Entomology and Zoology Studies 2018;6(1):128-187.

34. Suleiman M, Rugumamu CP, Ibrahim ND. Use of botanicals to suppress the development of maize weevil, Sitophilus zeamais Motsch. (Coleoptera: Curculionidae) in stored sorghum grains. Journal of Agriculture and Veterinary Science 2018;11(2):01-10. DOI: http://dx.doi.org/10.9790/2380-1102020110.

35. Chudasama JA, Sagarka NB, Sharma S. Deterrent effect of plant extracts against Callosobruchus maculatus on stored cowpea in Saurashtra (Guarat, India). J Appl Nat. Sci 2015;7:187-191.

36. Suleiman M, Ibrahim ND, Majeed Q. Control of Sitophilus zeamais (Motsch) [Coleoptera: Curculionidae] on sorghum using some plant powders. International Journal of Agriculture and Forestry 2012;2(1):53-57. DOI: http://dx.doi.org/10.5923/j.ijaf.20120201.09.

37. Adedire CO, Ajayi TS. Assessment of insecticidal properties of some plant extracts as grain protectants against the maize weevils, Sitophilus zeamais Motschulsky. Nigerian Journal of Entomology. 1996;13:93-338. 